\title{
The N-Terminal Region of the Readthrough Domain Is Closely Related to Aphid Vector Specificity of Soybean dwarf virus
}

\author{
Hidetaka Terauchi, Ken-ichiro Honda, Noriko Yamagishi, Seiji Kanematsu, Kiyoshi Ishiguro, and Soh Hidaka
}

First, third, fourth, fifth, and sixth authors: National Agricultural Research Center for Tohoku Region, Morioka, Iwate 020-0198, Japan; and second author: National Agricultural Research Center, Tsukuba, Ibaraki 305-8666, Japan.

Current address of H. Terauchi: Invitrogen Japan K.K. 35-4, Nihonbashi-Hamacho 2 Chome, Chuo-ku, Tokyo 103-0007, Japan.

Accepted for publication 15 August 2003.

\begin{abstract}
Terauchi, H., Honda, K., Yamagishi, N., Kanematsu, S., Ishiguro, K., and Hidaka, S. 2003. The $\mathrm{N}$-terminal region of the readthrough domain is closely related to aphid vector specificity of Soybean dwarf virus. Phytopathology 93:1560-1564.

It has been speculated that the N-terminal half of the readthrough domain (RTD) encoded by open reading frame 5 of Soybean dwarf virus (SbDV) is related to the vector specificity. To further investigate this hypothesis, transmissibility via aphids was tested on $17 \mathrm{SbDV}$ isolates and comparisons of the deduced amino acid sequences of the coat protein (CP) and other proteins encoded by the RTD were made between these isolates. Isolates were distinguished into four strains: YS, causing yel-

lowing in soybean and transmittable by Aulacorthum solani; DS, causing dwarfing and transmittable by $A$. solani; YP, causing yellowing and transmittable by Acyrthosiphon pisum; and DP, causing dwarfing and transmittable by A. pisum. Phylogenetic analysis showed that the trees for the $\mathrm{CP}$ and the C-terminal half of the RTD sequences contained clusters of isolates of the same symptom type, whereas the tree for the N-terminal half of the RTD contained clusters of isolates of the same aphid vector type. These results agreed with our previous data of the complete nucleotide sequences of four SbDV isolates, and strongly indicated a close relationship between the N-terminal half of the RTD amino acid sequences and aphid transmission specificity of SbDV.
\end{abstract}

Soybean dwarf virus (SbDV) causes serious damage to soybean production, especially in northern Japan $(24,25)$. In an earlier study, we classified SbDV isolates into four strains (YS, YP, DS, and DP) based on symptomatology in infected soybean plants (Glycine $\max ($ L.) Merr.) and on aphid vector specificity (26). YS and YP strains cause yellowing in soybean, and infect white clover (Trifolium repens L.) but not red clover (T. pratense L.) $(4,14,22)$. DS and DP strains cause dwarfing in soybean, and infect red clover but not white clover $(4,10,24)$. YS and DS strains are transmitted by the aphid vector Aulacorthum solani (Kaltenbach), whereas YP and DP strains are transmitted by both Acyrthosiphon pisum (Harris) and Nearctaphis bakeri (Cowen) (10,14,22). Moreover, the DS strain consists of two substrains which cause different degrees of dwarfing in soybean, namely, DS-severe (DS-S) and DS-mild (DS-M). These two substrains also have been documented as severe dwarfing (DS) and mild dwarfing (DM) strains, respectively $(23,24)$.

SbDV is a member of the family Luteoviridae and has a singlestranded positive-sense RNA genome of 5.7 to $5.9 \mathrm{~kb}$ encapsidated in a small isometric particle $(19,24,26)$. The genomic RNA consists of five open reading frames (ORFs). ORFs 1 and 2 encode the replication-related proteins, and ORF 4 putatively encodes a movement protein. ORF 3 encodes the coat protein (CP), which is the major component of the capsid, and ORF 5 encodes a readthrough domain (RTD), which probably is translated by inframe readthrough of the ORF 3 stop codon $(12,13,15,18,21)$. The minor component of the capsid is a truncated CP-RTD protein which consists of the $\mathrm{CP}$ and the N-terminal half of the RTD (NRTD) (11). It is well established that the minor capsid protein is

Corresponding author: S. Kanematsu; E-mail address: s0813@affrc.go.jp

Publication no. P-2003-1014-01R

(C) 2003 The American Phytopathological Society essential for aphid transmission of viruses in the family Luteoviridae $(1-3,21,27)$.

In a previous article, we documented the complete nucleotide sequences of representative isolates of the four SbDV strains and showed that sequence identity was highest between strains with the same symptomatology (26). However, although the deduced amino acid sequences of the RTD (especially the C-terminal half [C-RTD]) were very different between $\mathrm{Y}$ and D strains, those of the N-RTD were very similar between YS and DS and between YP and DP. Therefore, we speculated that the N-RTD is closely involved in aphid vector specificity of SbDV, and that SbDV acquired the four genotypes by evolutionary events resulting from either recombination between the ancestral Y and D strains which had been transmitted by different aphid species, or accumulation of mutations and strong selection pressure for vector specificity.

To further investigate this hypothesis, we examined the genomic nucleotide sequences of $17 \mathrm{SbDV}$ isolates in relation to aphid specificity and symptomatology in host plants.

\section{MATERIALS AND METHODS}

Virus isolates and aphid vectors. Sources of the $17 \mathrm{SbDV}$ isolates used in this study are summarized in Table 1. With the exception of DP isolate M96-1, which was isolated from a viruliferous aphid, all isolates were obtained from symptomatic soybean plants in the Hokkaido or Iwate Prefectures. All isolates were maintained in host plants through serial transmissions using Aulacorthum solani or Acyrthosiphon pisum as vectors. Nonviruliferous colonies of Aulacorthum solani and Acyrthosiphon pisum were collected in the Hokkaido Prefecture, and were raised on soybean and broad bean plants (Vicia faba L.), respectively.

Virus transmission test and northern blot analysis. To test the aphid vector specificity of each isolate, nonviruliferous aphids were given access to infected plants for a 72-h period. Ten aphids then were transferred to 2- to 3-week-old healthy soybean or 
broad bean seedlings for an inoculation period of $72 \mathrm{~h}$, after which the plants were sprayed with an insecticide. The presence of the virus in test plants was determined 6 weeks after inoculation by northern blot analysis. Total RNA for northern blot analysis was extracted from $0.1 \mathrm{~g}$ of leaf tissue using TRIzOL (Invitrogen Life Technology, Carlsbad, CA), and preparation of probes and hybridization were performed using the AlkPhos Direct Labeling and Detection System (Amersham Biosciences, Piscataway, NJ).

RNA extraction and cDNA cloning and sequencing. Viral RNA used for cDNA cloning was extracted from infected leaf material $(\approx 1 \mathrm{~g})$ using the guanidine thiocyanate method followed by ultra-centrifugation (20). The pellet was resuspended in TrisEDTA buffer, extracted twice with a phenol-chloroform mixture and then once with chloroform. The RNA then was precipitated with ethanol. The viral RNA was converted to cDNA using reverse transcriptase, and the cDNA was amplified by polymerase chain reaction (PCR) using Ex Taq polymerase (Takara, Japan) and the following primer pairs: SD3381+ and SD5360 - for YS, SD3381+ and SD5320 for YP, and SD3381+ and SD5442- for DS and DP. The amplified region is shown in Figure 1A and the primer sequences were as follows: SD3381+, 5'CTTCCACCTCGTCAGGCTCC3', homologous to nucleotide positions 3,384 to 3,403 of the YS (M93-1) genome; SD5320-, 5'ACAAACGCCCGAGATTACCG3', complementary to positions 5,293 to 5,312 of the YP (M94-1) genome; SD5360-, 5'CATACTGTGTTGATACGACG3', complementary to positions 5,334 to 5,353 of the YS (M93-1) genome; and SD5442-, 5'CTGTTAACTCAGCGGCAGTG3', complementary to positions 5,422 to 5,441 of the DSM (HS97-8) genome.

The PCR products of each isolate were inserted into the pT7Blue T-vector (Novagen, Madison, WI) by TA cloning and the resultant plasmids were introduced into Escherichia coli JM109. Plasmid inserts were sequenced using fluorescent BigDye terminators and an ABI PRISM 310 sequencer (Applied Biosystems, Foster City, CA). The nucleotide sequence was determined using at least three independent clones and sequencing both strands of all the clones.

Computer analysis of sequences. The ORF 5 sequences of SbDV isolates were analyzed using the ClustalX program (9). Phylogenetic trees were constructed by the neighbor-joining method, and a bootstrap value was calculated on 1,000 trials for statistical validity, then displayed using the Tree View PPC program.

\section{RESULTS}

Analysis of biological properties. In all, $17 \mathrm{SbDV}$ isolates obtained from the Hokkaido and Iwate Prefectures were classified into YS (nine isolates), YP (three isolates), DS (four isolates), and DP (one isolate) strains based on symptomatology and aphid specificity (Table 1). All isolates of YS and YP strains caused yellowing and shrinking of leaves in soybean. Three isolates of DS-M (HS97-8, HS99-2, and HS99-4) caused mild leaf epinasty and slight shortening of internodes in soybean, whereas isolate DS-S (HS99-5) caused severe leaf curl and extreme dwarfing. One DP isolate (M96-1) caused severe leaf curl and dwarfing, symptoms similar to those caused by DS-S (HS99-5).

In the determination of infection status by northern blot analysis, bands of $\approx 6$ and $3 \mathrm{~kb}$, corresponding to genomic and subgenomic RNAs of the virus, respectively, were detected in all symptomatic plants (Fig. 1B). These viral RNAs also were detected in large amounts in broad bean plants with indefinite symptomatology. Although A. pisum preferred broad bean to soybean as a host plant, most isolates were transmitted by both vector species in approximately equal proportions (60\% or more); only the isolate DP (M96-1) was not very efficiently transmitted (28\%). This may have been due to its relatively low affinity for the A. pisum clone used in the test, because the transmission efficiency of SbDV is known to vary among aphid populations (6).

Analysis of the deduced amino acid sequences encoded by ORF 3 and ORF 5. In addition to our previously reported data (26), the genomic sequences of 13 new isolates were determined here for an $\approx 2$-kb region of RNA which contained the C-terminal half of the CP (C-CP) gene and the RTD gene (Fig. 1A). Sequencing and phylogenetic analysis were performed separately for each of the three regions of the CP-RTD fusion protein; 82 amino acid (aa) residues in the $C$ terminus of the $C P$ gene, 261 aa residues in the $\mathrm{N}$ terminus of the RTD gene, and 226 to 261 aa residues in the $\mathrm{C}$ terminus of the RTD gene (Fig. 1A). The amino acid sequence identities between isolates are summarized for each

TABLE 1. Summary of the origin, biological properties, and cluster type for Soybean dwarf virus (SbDV) isolates used in this study

\begin{tabular}{|c|c|c|c|c|c|c|c|c|c|}
\hline \multirow[b]{2}{*}{ Isolates } & \multicolumn{2}{|c|}{ Isolate origin } & \multirow[b]{2}{*}{ Symptom in soybean } & \multicolumn{2}{|c|}{ Aphid transmissibility ${ }^{\mathrm{a}}$} & \multicolumn{3}{|c|}{ Cluster $^{\mathrm{b}}$} & \multirow[b]{2}{*}{ Accession no. ${ }^{\mathrm{c}}$} \\
\hline & Region & Year & & Aulacorthum solani & Acyrthosiphon pisum & $\mathrm{C}-\mathrm{CP}$ & N-RTD & C-RTD & \\
\hline M93-1 ${ }^{d}$ & Iwate & 1993 & Yellowing & $37 / 48$ & $0 / 20$ & $\mathrm{Y}$ & $\mathrm{S}$ & $\mathrm{Y}$ & AB038147 \\
\hline HD99-3 & Hokkaido & 1999 & Yellowing & + & nt & $\mathrm{Y}$ & $\mathrm{S}$ & $\mathrm{Y}$ & AB076047 \\
\hline HD99-4 & Hokkaido & 1999 & Yellowing & + & nt & $\mathrm{Y}$ & $\mathrm{S}$ & $\mathrm{Y}$ & AB076048 \\
\hline HN94-1 & Hokkaido & 1994 & Yellowing & $6 / 7$ & $0 / 7$ & $\mathrm{Y}$ & $\mathrm{S}$ & $\mathrm{Y}$ & AB076040 \\
\hline T95-1 & Iwate & 1995 & Yellowing & + & nt & $\mathrm{Y}$ & $\mathrm{S}$ & $\mathrm{Y}$ & AB076039 \\
\hline IK00-1 & Iwate & 2000 & Yellowing & $25 / 29(64 / 69)$ & $0 / 10(0 / 10)$ & $\mathrm{Y}$ & $\mathrm{S}$ & $\mathrm{Y}$ & AB076041 \\
\hline IK00-2 & Iwate & 2000 & Yellowing & $16 / 22$ & nt & $\mathrm{Y}$ & $\mathrm{S}$ & $\mathrm{Y}$ & AB076042 \\
\hline IIO0-1 & Iwate & 2000 & Yellowing & $24 / 36(74 / 84)$ & $0 / 10(0 / 10)$ & $\mathrm{Y}$ & $\mathrm{S}$ & $\mathrm{Y}$ & AB076043 \\
\hline IIOO-2 & Iwate & 2000 & Yellowing & $14 / 20$ & nt & $\mathrm{Y}$ & $\mathrm{S}$ & $\mathrm{Y}$ & AB076044 \\
\hline M94-1 ${ }^{\mathrm{d}}$ & Iwate & 1994 & Yellowing & $0 / 10(0 / 14)$ & $21 / 34(46 / 72)$ & $\mathrm{Y}$ & $\mathrm{P}$ & $\mathrm{Y}$ & $\mathrm{AB} 038148$ \\
\hline IT00-1 & Iwate & 2000 & Yellowing & $0 / 12(0 / 13)$ & $13 / 20(36 / 48)$ & $\mathrm{Y}$ & $\mathrm{P}$ & $\mathrm{Y}$ & AB076045 \\
\hline IT00-2 & Iwate & 2000 & Yellowing & $0 / 10(0 / 15)$ & $16 / 24(40 / 47)$ & $\mathrm{Y}$ & $\mathrm{P}$ & $\mathrm{Y}$ & AB076046 \\
\hline HS97- $8^{d}$ & Hokkaido & 1997 & Dwarfing (mild) & $8 / 11(6 / 10)$ & $0 / 12(0 / 12)$ & $\mathrm{D}$ & $\mathrm{S}$ & $\mathrm{D}$ & AB038149 \\
\hline HS99-2 & Hokkaido & 1999 & Dwarfing (mild) & + & nt & $\mathrm{D}$ & $\mathrm{S}$ & $\mathrm{D}$ & AB076049 \\
\hline HS99-4 & Hokkaido & 1999 & Dwarfing (mild) & + & nt & $\mathrm{D}$ & $\mathrm{S}$ & $\mathrm{D}$ & AB076050 \\
\hline HS99-5 & Hokkaido & 1999 & Dwarfing (severe) & $26 / 30(8 / 10)$ & $0 / 12(0 / 8)$ & $\mathrm{D}$ & $\mathrm{S}$ & $\mathrm{D}$ & AB076038 \\
\hline M96-1 $1^{\mathrm{d}, \mathrm{e}}$ & Iwate & 1996 & Dwarfing (severe) & $0 / 10$ & $7 / 25$ & $\mathrm{D}$ & $\mathrm{P}$ & $\mathrm{D}$ & AB038150 \\
\hline
\end{tabular}

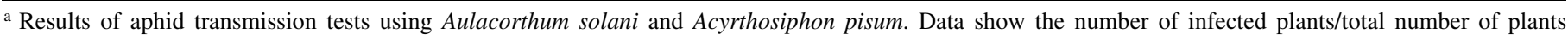
inoculated; $+=$ not counted but efficiently and routinely transmitted for maintenance purposes in our laboratory; nt $=$ no tests run. Data without parentheses indicate the results for soybean and those in parentheses indicate the results for broad bean.

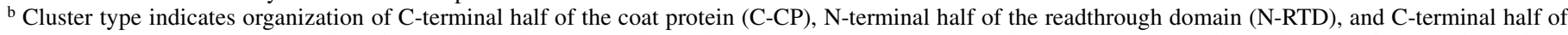
the RTD (C-RTD) types determined from amino acid sequence identities. C-CP, N-RTD, and C-RTD include the last 82 amino acids (aa) of CP, the first 261 aa of the RTD, and the remaining sequences of the RTD, respectively.

c Accession number of DDBJ, EMBL, and GenBank.

d Representative isolates of each strain analyzed in the previous study (26).

e Isolate DP (M96-1) was isolated from a viruliferous aphid that was trapped in a field. 
strain in Table 2, and phylogenetic relationships are represented separately for the three regions in Figure 2.

Multiple alignments of amino acid sequences showed that the C-CP sequences of the same symptom-type isolates were highly conserved. There were 97.6 to $100 \%$ identities between isolates of the same strain or between isolates of the same symptom-type strains. The sequence variability between different symptom-type isolates was greater, such that the amino acid identities were lower (89.2 to $90.4 \%$ ) (Table 2). As a consequence, SbDV isolates were distinguished into two distinct groups in the $\mathrm{C}-\mathrm{CP}$ region, and the phylogenetic tree contained two clusters, $\mathrm{Y}$ and D. The $\mathrm{Y}$ cluster consisted of all YS and YP isolates, and the D cluster consisted of all DS and DP isolates (Fig. 2A). The C-terminal half of the $20-\mathrm{kDa}$ protein encoded by ORF 4, which overlapped completely with ORF 3 , also was analyzed. The phylogenetic tree had a similar overall cluster organization to the CP but with some differences in the relationships between isolates (data not shown).

Phylogenetic analysis of the RTD amino acid sequences showed quite different cluster organizations for the $\mathrm{N}$ - and $\mathrm{C}$-terminal re-

A

B

CP RTD

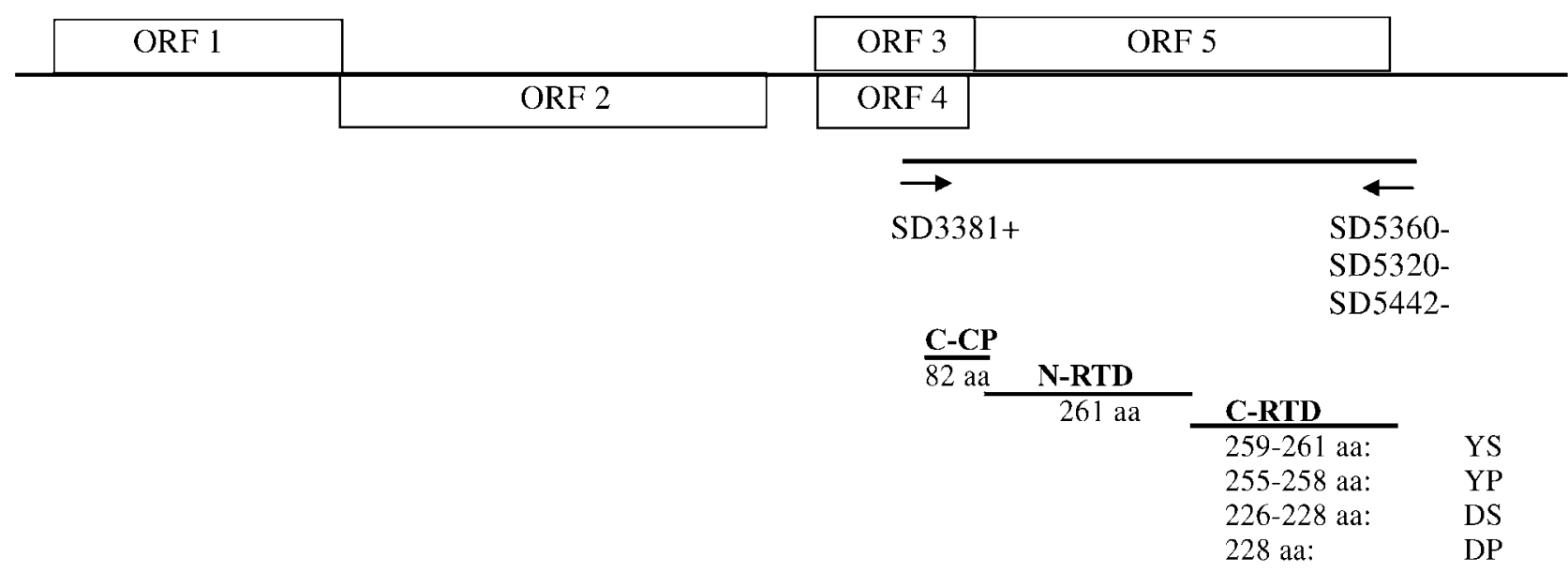

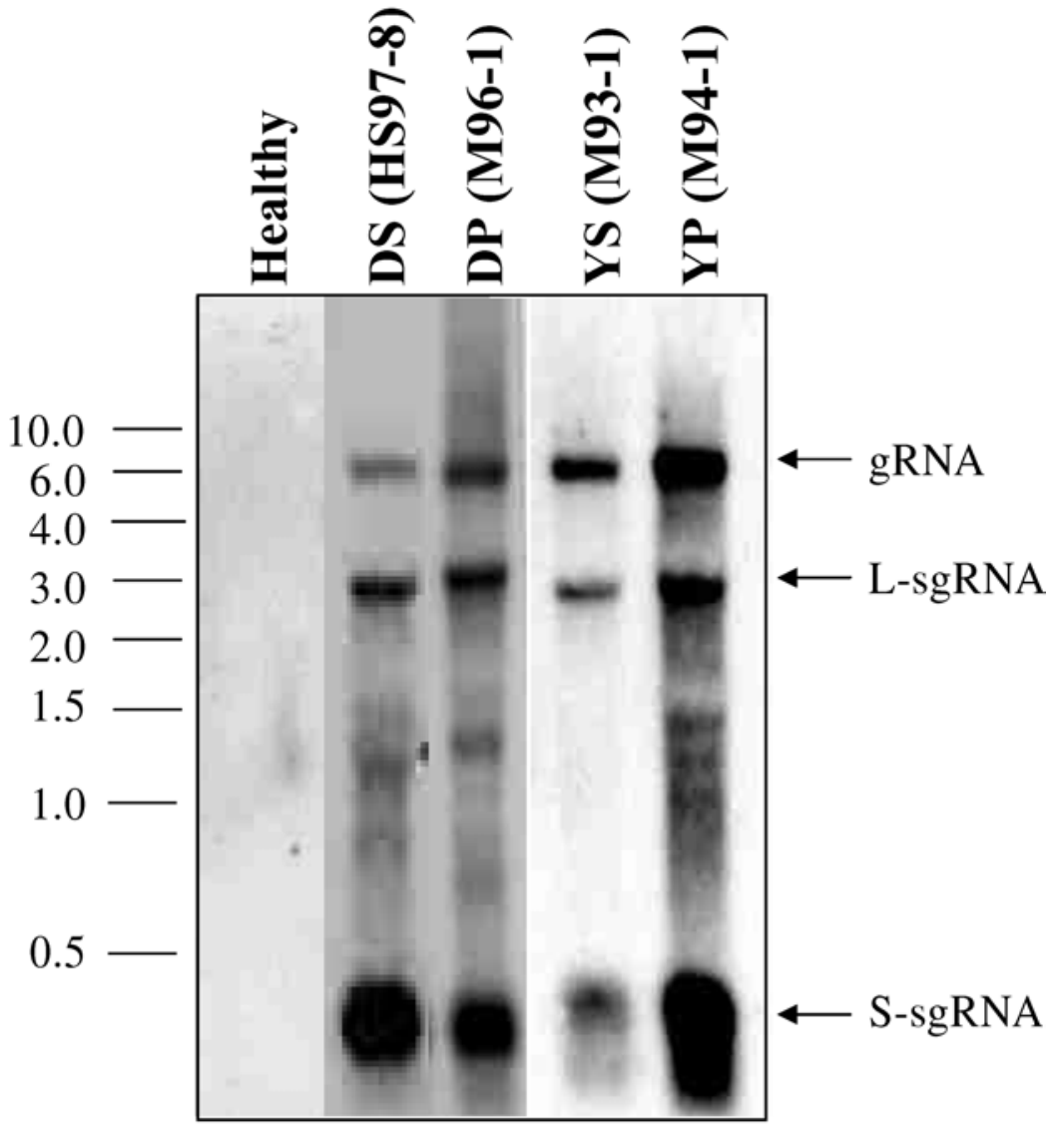

Fig. 1. A, Map of part of the Soybean dwarf virus (SbDV) genome, showing location of primers used in this study and the regions used for phylogenetic analysis. Open reading frames (ORFs) 1 and 2 encode the replication-related proteins; ORF 3 encodes the viral coat protein (CP); ORF 4 putatively encodes a movement protein; the readthrough domain (RTD) specified by ORF 5 possibly encodes the aphid transmission factor. B, Northern blot analysis of the total RNA extracted from the healthy and infected leaves with four SbDV strains. Probes used are specific for the 3' region of D strains or Y strains. Genomic RNA (gRNA), large subgenomic RNA (L-sgRNA), and small subgenomic RNA (S-sgRNA) are indicated. The relative position of RNA size markers in kilobases is shown on the left. 
gions (Fig. 2B and C). The tree for the N-RTD amino acid sequences contained two distinct clusters, an $\mathrm{S}$ cluster consisting of all YS and DS isolates and a P cluster consisting of all YP and DP isolates. The sequence identities between isolates in the $\mathrm{S}$ cluster were 96.9 to $100 \%$ and in the $\mathrm{P}$ cluster were 93.5 to $99.2 \%$, whereas there were 83.5 to $87.0 \%$ identities between isolates differing in aphid specificity (Table 2).

In contrast, the phylogenetic tree for the C-RTD amino acid sequences contained Y and D clusters, and its topology and organization were similar to that obtained for the C-CP sequences. However, the trees had some differences in the relationships between isolates. The most notable difference was the branch length between the $\mathrm{Y}$ and D clusters (Fig. 2A and C). There were 15.7 to $21.7 \%$ identities between $\mathrm{Y}$ and $\mathrm{D}$ strains, whereas sequence comparisons between isolates of the same symptomatology revealed considerable sequence variation, with identities between 85.0 and 98.8\% (Table 2).

The Australian isolate Tas-1 also was analyzed together with the Japanese isolates. It was grouped into a Y cluster according to its $\mathrm{C}-\mathrm{CP}$ and $\mathrm{C}-\mathrm{RTD}$ sequences, and into an $\mathrm{S}$ cluster according to its N-RTD sequence (data not shown). This agrees with the report that Tas-1 is transmitted by Aulacorthum solani but not by Acyrthosiphon pisum (8).

TABLE 2. Amino acid sequence identities of the C-terminal half of the $\mathrm{CP}$ (C-CP) and the N- and C-terminal halves of the RTD (N-RTD and C-RTD) for 17 isolates of Soybean dwarf virus ${ }^{\mathrm{a}}$

\begin{tabular}{ccccc}
\hline & YS & YP & DS & DP \\
\hline YS & $97.6-100$ & $97.6-98.8$ & 90.4 & 90.4 \\
& $97.7-100$ & $83.5-85.4$ & $96.9-98.5$ & $83.9-85.1$ \\
& $85.0-98.1$ & $85.0-98.1$ & $15.9-21.7$ & $16.9-18.4$ \\
YP & $\ldots$ & $98.8-100$ & 89.2 & 89.2 \\
& $\ldots$ & $97.7-99.2$ & $85.4-87.0$ & $93.5-94.3$ \\
& $\ldots$ & $95.0-98.8$ & $15.7-18.1$ & $16.9-18.4$ \\
DS & $\ldots$ & $\ldots$ & 100 & 98.8 \\
& $\ldots$ & $\ldots$ & $99.2-100$ & $85.8-86.2$ \\
& $\ldots$ & $\ldots$ & $88.2-97.8$ & $89.9-91.7$ \\
\hline
\end{tabular}

${ }^{a}$ Percentage of amino acid sequence identities calculated for all possible comparisons between isolates. The relationships between DP and DP strains are omitted because there was only a single isolate, M96-1. The upper, middle, and bottom rows of data for each strain designate identity ranges for the $\mathrm{C}-\mathrm{CP}, \mathrm{N}-\mathrm{RTD}$, and C-RTD, respectively.

\section{DISCUSSION}

In recent years, the SbDV-YS strain has been most prevalent in northern Japan and frequently has been isolated from diseased soybean. Both YP and DS strains also have been found to a lesser extent, particularly in the Iwate and Hokkaido Prefectures, but the DP strain rarely has been found in the field. The isolate DP (M961) was obtained from a viruliferous aphid which was trapped in a field by chance (10). Symptom observations and aphid specificity tests indicated that all the isolates used in this study were distinguishable into the four strains previously reported (26).

In aphid specificity tests, isolates were transmitted by either Aulacorthum solani or Acyrthosiphon pisum. This result agrees with previous reports that SbDV isolates are transmitted exclusively by one of these two aphid species $(5,10,14,24)$, and that the vector specificity between $\mathrm{SbDV}$ isolate and aphid species is very high compared with that of other viruses in the family Luteoviridae $(7,16,17,21)$. However, considering that $N$. bakeri as well as A. pisum can transmit the isolates YP (M94-1) and DP (M96-1) (10), these two aphid species may have similar transmission factors which closely interact with the particles of YP and DP strains.

Phylogenetic analyses showed that all of the same symptomtype isolates were closely related in terms of C-CP and C-RTD sequences. A similar relationship was proposed previously for the replicase gene encoded by ORF 1 and ORF 2 (26). In contrast, all of the same vector-type isolates were closely related in terms of $\mathrm{N}-\mathrm{RTD}$ sequences rather than $\mathrm{C}-\mathrm{CP}$ or C-RTD sequences. This result agrees with our previous report of the existence of conserved amino acid sequences between the same vector-type isolates in the $\mathrm{N}-\mathrm{RTD}$ but not in the CP region (26). Although we have not yet been able to prove experimentally whether the CP or RTD carries the major determinants regulating vector specificity, the circumstantial evidence obtained in this study strongly supports our hypothesis that an N-RTD rather than a CP sequence determines aphid transmission specificity of SbDV. We presume that certain sequences in the N-RTD regulate the interaction in some way with transmission factors of vector aphid species, and thus determine vector specificity.

The RTD has determinants for aphid specificity and symptomtype in the $\mathrm{N}$ - and C-halves, respectively. N-RTD is located in the center of the CP-RTD fusion protein and is translated by means of a subgenomic RNA, starting from a site between ORF 2 and ORF 3. Although it might be expected from this that the N-RTD

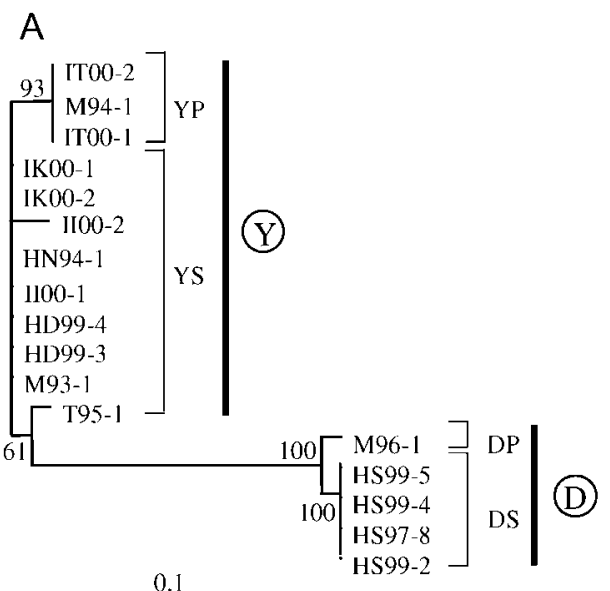

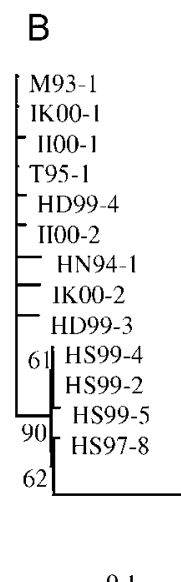

0.1

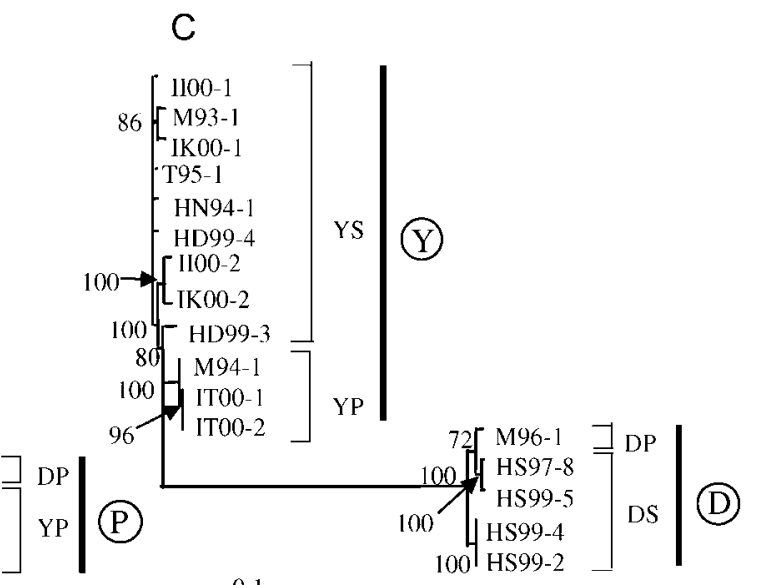

$\underline{0.1}$

Fig. 2. Phylogenetic trees for the deduced amino acid sequences of the A, C-terminal half of the coat protein, B, N-terminal half of the readthrough domain (RTD), and C, C-terminal half of the RTD. Definitions are given in the text. Brackets indicate single-strain subclusters and thick bars indicate main clusters. Scales for branch lengths are shown below each tree. Y and D show clusters of same symptom-types (Y: yellowing, D: dwarfing). S and P show clusters of same aphid transmission specificities (S: Aulacorthum solani, P: Acyrthosiphon pisum). Trees were constructed by the neighbor-joining method with 1,000 bootstraps using the ClustalX alignment program, and displayed by the Tree View PPC program. Bootstrap values (\%) are indicated at each node. The branch length of each unrooted tree is displayed in proportion to the amount of evolutionary distance between sequences within the tree, and is not comparable between trees. 
naturally would evolve together with $\mathrm{CP}$ and C-RTD, the N-RTD appears to have evolved along a different course. We speculate that SbDV evolved into four strains in the following way. The original SbDV consisted of two ancestral strains, Y and D, with each strain transmitted exclusively by either Aulacorthum solani or Acyrthosiphon pisum. The acquirement of differences in pathogenicity and aphid specificity probably resulted from evolutionary divergence of the two populations due to discrimination for principal hosts; namely, white or red clover. With the increasing availability of soybean as a potential host for both strains, the ancestral $\mathrm{Y}$ and D strains then exchanged the N-RTD by recombination, thereby generating the four strains. An alternative scenario is that the N-RTD was more susceptible to mutations, some of which led to the evolution of efficient aphid transmission systems, whereas the $\mathrm{CP}$ and C-RTD changed very little over time.

Analyses using infectious cDNA clones are necessary to prove unambiguously a relationship between the N-RTD sequences and aphid transmission specificity, and we are now actively engaged in such investigations. The data described in this article have provided a useful basis from which to target genes responsible for aphid specificity.

\section{LITERATURE CITED}

1. Brault, V., Van den Heuvel, J. F. J. M., Verbeek, M., Ziegler-Graff, V., Reutenauer, A., Herrbach, E., Garaud, J.-C., Guilley, H., Richards, K., and Jonard, G. 1995. Aphid transmission of beet western yellows luteovirus requires the minor capsid read-through protein P74. EMBO J. $14: 650-659$.

2. Bruyére, A., Brault, V., Zieglar-Graff, V., Simonis, M.-T., Van den Heuvel, J. F. J. M., Richards, K., Guilley, H., Jonard, G., and Herrbach, E. 1997. Effects of mutations in the beet western yellows virus readthrough protein on its expression and packaging and on virus accumulation, symptoms, and aphid transmission. Virology 230:323-334.

3. Chay, C. A., Gunasinge, U. B., Dinesh-Kumar, S. P., Miller, W. A., and Gray, S. M. 1996. Aphid transmission and systemic plant infection determinants of barley yellow dwarf luteovirus-PAV are contained in the coat protein readthrough domain and $17-\mathrm{kDa}$ protein, respectively. Virology 219:57-65.

4. Damsteegt, V. D. 1990. Soybean dwarf virus: Experimental host range, soybean germ plasm reactions, and assessment of potential threat to U.S. soybean production. Plant Dis. 74:992-995.

5. Damsteegt, V. D., Stone, A. L., Russo, A. J., Luster, D. G., Gildow, F. E., and Smith, O. P. 1999. Identification, characterization, and relatedness of luteovirus isolates from forage legumes. Phytopathology 89: 374-379.

6. Damsteegt, V. D., and Voegtlin, D. J. 1990. Morphological and biological variation among populations of Aulacorthum solani (Homoptera: Aphididae), the vector of soybean dwarf virus. Ann. Entomol. Soc. Am. 83:949-955.

7. Gildow, F. E. 1993. Evidence for receptor-mediated endocytosis regulating luteovirus acquisition by aphids. Phytopathology 83:270-277.
8. Helms, K., Waterhouse, P. M., and Carver, M. 1983. Aulacorthum (Neomyzus) clrcumflexum, a vector of subterranean clover red leaf virus. Aust. Plant Pathol. 12:66-67.

9. Higgins, D. G., Bleasby, A. J., and Fuchs, R. 1992. Clustal V: Improved software for multiple sequence alignment. Comput. Appl. Biosci. 8:189191.

10. Honda, K., Kanematsu, S., and Mikoshiba, Y. 1999. Dwarfing strain of soybean dwarf luteovirus transmitted by Nearctaphis bakeri and Acyrthosiphon pisum. Ann. Phytopathol. Soc. Jpn. 65:387. (Abstract in Japanese.)

11. Komatsuda, J., Terauchi, H., Kanematsu, S., Isogai, M., and Yoshikawa, N. 2001. Production of antisera against N-terminal and C-terminal regions of the read-through domain encoded by Soybean dwarf virus (YS strain) genome. Jpn. J. Phytopathol. 68:53. (Abstract in Japanese.)

12. Martin, R. R., Keese, P. K., Young, M. J., Waterhouse, P. M., and Gerlach, W. L. 1990. Evolution and molecular biology of luteoviruses. Annu. Rev. Phytopathol. 28:341-363.

13. Mayo, M. A., and Ziegler-Graff, V. 1996. Molecular biology of luteoviruses. Adv. Virus Res. 46:413-460.

14. Mikoshiba, Y., Fujisawa, I., and Honda, K. 1991. A new strain of soybean dwarf virus transmitted by Acyrthosiphon pisum in Japan. Ann. Phytopathol. Soc. Jpn. 57:448. (Abstract in Japanese.)

15. Miller, W. A., Dinesh-Kumar, S. P., and Paul, C. P. 1995. Luteovirus gene expression. Crit. Rev. Plant Sci. 14:179-211.

16. Miller, W. A., and Rasochová, L. 1997. Barley yellow dwarf viruses. Annu. Rev. Phytopathol. 35:167-190.

17. Peiffer, M. L., Gildow, F. E., and Gray, S. M. 1997. Two distinct mechanisms regulate luteovirus transmission efficiency and specificity at the aphid salivary gland. J. Gen. Virol. 78:495-503.

18. Rathjen, J. P., Karageorgos, L. E., Habili, N., Waterhouse, P. M., and Symons, R. H. 1994. Soybean dwarf luteovirus contains the third variant genome type in the luteovirus group. Virology 198:671-679.

19. Regenmortel, M. H. V., Fauquet, C. M., and Bishop, D. H. L. 2000. Virus Taxonomy. Pages 775-784 in: Seventh Report of the International Committee on Taxonomy of Viruses. Academic Press, New York.

20. Sambrook, J., Fritsch, E. F., and Maniatis, T. 1989. Molecular Cloning: A Laboratory Manual. 2nd ed. Cold Spring Harbor Laboratory, Cold Spring Harbor, NY.

21. Smith, H. G., and Barker, H. 1999. The Luteoviridae. CABI Publishing, UK.

22. Tamada, T. 1970. Aphid transmission and host range of soybean dwarf virus. Ann. Phytopathol. Soc. Jpn. 36:266-274.

23. Tamada, T. 1973. Strains of soybean dwarf virus. Ann. Phytopathol. Soc. Jpn. 39:27-34.

24. Tamada, T. 1975. Studies on the soybean dwarf disease. Rep. Hokkaido Prefect. Agric. Exp. Stn. 25:1-144. (In Japanese with English abstract.)

25. Tamada, T., Goto, T., Chiba, I., and Suwa, T. 1969. Soybean dwarf, a new virus disease. Ann. Phytopathol. Soc. Jpn. 35:282-285.

26. Terauchi, H., Kanematsu, S., Honda, K., Mikoshiba, Y., Ishiguro, K., and Hidaka, S. 2001. Comparison of complete nucleotide sequences of genomic RNAs of four Soybean dwarf virus strains that differ in their vector specificity and symptom production. Arch. Virol. 146:1885-1898.

27. Wang, J. Y., Chay, C., Gildow, F. E., and Gray, S. M. 1995. Readthrough protein associated with virions of barley yellow dwarf luteovirus and its potential role in regulating the efficiency of aphid transmission. Virology 206:954-962. 